\title{
Uma análise semiótica de atividades de modelagem matemática mediadas pela tecnologia
}

\author{
Karina Alessandra Pessôa da Silva \\ Adriana Helena Borssoi \\ Lourdes Maria Werle de Almeida
}

\begin{abstract}
Resumo
Neste trabalho apresentamos uma análise semiótica de atividades de modelagem matemática mediadas pelo uso da tecnologia. Levando em consideração que a modelagem é uma alternativa pedagógica na qual fazemos uma abordagem matemática para fenômenos não essencialmente matemáticos, propusemos em um minicurso de curta duração, desenvolvido com participantes de um evento regional, duas atividades na qual o fenômeno em estudo corresponde ao percurso realizado por um objeto lançado para o alto e à frente e o realizado por um carrinho de fricção. O que podemos inferir é que os participantes (intérpretes) produziram de imediato, signos distintos para os movimentos que estão relacionados ao mesmo objeto matemático. $\mathrm{O}$ uso do software de videoanálise Tracker possibilitou aos participantes visualizarem a produção de dados que fizeram emergir o objeto matemático representado em cada movimento.
\end{abstract}

Palavras-chave: modelagem matemática, tecnologia, semiótica peirceana.

\begin{abstract}
In this paper we present a semiotic analysis of mathematical modeling activities mediated by the use of technology. Taking into account that modeling is an educational alternative in which we do a mathematical approach to not essentially mathematical phenomena, we proposed in a short course, developed with participants an regional event, two activities in which the phenomenon under study corresponds to the route performed by an object thrown upward and forward and carried out by a cart friction. What we can infer is that immediately the participants (interpreters) produced distinct signs for movements that are related to the same mathematical object. Using the Tracker video analysis software enabled the participants visualize the production of data that did emerge from the mathematical object represented in every movement.
\end{abstract}

Keywords: mathematical modeling, technology, Peircean semiotics.

\section{Introdução}

Neste texto expressamos um viés que considera o desenvolvimento de atividades de modelagem matemática amparado pelo uso da tecnologia enquanto aliada para o ensino de

DOI: Em andamento. 
conteúdos matemáticos. Esse propósito atende também à demanda de pesquisas, no que diz respeito ao uso de suportes teóricos que possibilitam a realização de inferências quando se trata de ensino de conteúdos matemáticos (CUNNINGHAM; KEHLE, 2003, STEINBRING, 2006, BERGER, 2010, MANECHINE; CALDEIRA, 2010, ALMEIDA; SILVA, 2014).

Inúmeras pesquisas trazem o entendimento de que ambientes de ensino e aprendizagem devem ser pensados de modo a considerar o potencial das tecnologias de informação e comunicação que estão disponíveis atualmente à grande parte da sociedade. Nesse sentido, a modelagem matemática como alternativa pedagógica pode se valer desses recursos tecnológicos como uma oportunidade de promover experiências de ensino em que os alunos possam aprender fazendo.

No que se refere à prática de modelagem, nessa ocasião, nos reportamos a um contexto em que atividades foram pensadas, propostas e desenvolvidas em um ambiente em que recursos tecnológicos são entendidos como elementos mediadores, com potencial para permear o desenvolvimento das atividades, desde a coleta de dados até a obtenção do modelo. Para esse propósito, a videoanálise é uma opção apropriada em nosso entendimento.

A Semiótica Peirceana é o constructo teórico por meio do qual as atividades, bem como algumas considerações dos participantes, de um curso de curta duração foram analisadas tomando como fonte de informação os registros de vídeo, imagens e arquivos eletrônicos do decorrer de seu desenvolvimento.

Com essa abordagem nos propomos a investigar os signos interpretantes produzidos pelos intérpretes em atividades de modelagem matemática ao fazer uso da tecnologia. Com esse objetivos pretendemos contribuir com o debate que visa ampliar as pesquisas em modelagem matemática ao mesmo tempo em que fortalece a Educação Matemática. A Educação Matemática é uma área de pesquisa que, de forma geral, defende uma abordagem dos conteúdos matemáticos capaz de contemplar o contexto social do aluno e suas individualidades, representa uma ação entre humanos. Essa ação é caracterizada pela intervenção de um sobre o outro, em que um educa e ou outro se deixa educar; um ensina e o outro se deixa ensinar; um que constrói conhecimento e o outro que permite que o conhecimento em si seja construído.

O nosso artigo contempla, além dessa introdução, quatro seções subsequentes. A primeira é destinada ao nosso entendimento sobre modelagem matemática na Educação Matemática enquanto alternativa pedagógica para o ensino de conteúdos matemáticos. Além de explicitarmos nosso entendimento sobre essa alternativa pedagógica, apresentamos alguns conceitos e definições que se fazem necessários para situar o leitor ao referenciá-los. Em seguida, tratamos da tecnologia enquanto parceira intelectual que possibilita mediar o desenvolvimento das atividades de modelagem. A terceira seção é destinada a algumas abordagens sobre a semiótica desenvolvida por Peirce e consiste no referencial teórico que nos possibilita inferir 
sobre os signos produzidos no desenvolvimento de atividades de modelagem mediadas pela tecnologia. As atividades desenvolvidas no minicurso são descritas em seção seguinte na qual apontamos os encaminhamentos realizados. Para fazermos o diálogo teórico, apresentamos na seção intitulada Articulação entre tecnologia e semiótica nestas atividades de modelagem uma análise semiótica das atividades desenvolvidas. Finalizamos com considerações e reflexões sobre a análise empreendida.

\section{Modelagem Matemática: nossos entendimentos}

Atividades de modelagem matemática, ao mesmo tempo em que proporcionam ao aluno o envolvimento com uma situação-problema, também visam desenvolver no aluno o que Galbraith (2012) chama de 'infraestrutura intelectual', de modo que os alunos possam se tornar usuários dos conhecimentos matemáticos construídos e resolver problemas de forma independente em diferentes situações dentro e fora do ambiente escolar.

Em algumas situações abordadas por meio da modelagem, os alunos se deparam diante de um obstáculo para o qual não possuem, provisoriamente, conhecimentos suficientes para superá-lo, emergindo assim a necessidade de construir esse conhecimento por meio dessa atividade. Logo, em modelagem, os alunos tanto ressignificam conceitos já construídos quanto constroem outros diante da necessidade de seu uso.

A construção e ressignificação de conceitos são associadas a ações dos alunos durante as atividades, como: a busca de informações; a identificação e seleção de variáveis; a elaboração de hipóteses; a simplificação; a transição de linguagens; a ativação de conhecimentos prévios; o uso de técnicas e/ou procedimentos matemáticos; a comparação e distinção de ideias; a generalização de fatos; a articulação de conhecimentos de diferentes áreas; a argumentação para expor para outros o julgamento do valor de teorias e métodos usados no desenvolvimento da atividade. Estas ações, de modo geral subsidiam a construção de um modelo matemático.

Segundo Lesh (2010), um modelo matemático é um sistema conceitual, descritivo ou explicativo, expresso por meio de uma linguagem ou uma estrutura matemática, com a finalidade de descrever o comportamento de outro sistema e permitir a realização de previsões sobre este outro sistema. Ainda de acordo com o autor, é possível que o modelo construído para representar uma situação num dado momento sirva, também, para representar outro sistema em um momento posterior. Em termos da realidade, o modelo matemático deve ser considerado sua representação simplificada.

No que se refere à introdução de atividades de modelagem nas aulas de matemática, embora as discussões estejam centradas no planejamento do professor, vale ponderar que atividades desse tipo também podem ser desafiadoras e não usuais para os estudantes.

R. B. E. C. T., vol 8, núm. 1, jan-abr.2015 ISSN - 1982-873X

DOI: Em andamento. 
Visando esclarecer nosso entendimento do que é uma atividade de modelagem matemática no contexto educacional citamos Almeida, Silva e Vertuan (2012, p. 12) que definem:

"de modo geral, uma atividade de Modelagem Matemática pode ser descrita em termos de uma situação inicial (problemática), de uma situação final desejada (que representa uma solução para a situação inicial) e de um conjunto de procedimentos e conceitos necessários para passar da situação inicial para a situação final. Nesse sentido, relações entre a realidade (origem da situação inicial) e Matemática (área em que os conceitos e os procedimentos estão ancorados) servem de subsídio para que conhecimentos matemáticos e não matemáticos sejam acionados e/ou produzidos $e$ integrados. A essa situação inicial problemática chamamos situação-problema; à situação final desejada associamos uma representação matemática, um modelo matemático".

Conforme os autores, uma atividade de modelagem compreende a seguinte estrutura: i) Situação inicial (problemática); ii) Fase de inteiração (Quais são os dados? Como obtê-los?; Definição de um problema; Que elementos devem ser levados em conta na observação?); iii) Matematização e resolução (hipóteses, variáveis, modelo matemático); iv) Interpretação e validação (análise do modelo); v) Situação final (uso do modelo).

Nesse encaminhamento Almeida, Silva e Vertuan (2012) também apontam que o uso do computador promove a aproximação e a interação dos fatos da realidade com o conteúdo acadêmico, pois entre outros aspectos, "possibilita lidar com as situações-problema por meio de simulações numéricas ou gráficas, variando parâmetros nas representações gráficas e (ou) algébricas" (ALMEIDA; SILVA; VERTUAN, 2012. p. 32).

Antes de descrevermos as atividades de modelagem que intencionamos, vamos dedicar a próxima seção para evidenciar nossa compreensão sobre os recursos tecnológicos e definir nossas opções para os propósitos deste trabalho.

\section{Tecnologia: parceira intelectual}

As novas tecnologias oferecem oportunidades para a criação de ambientes de aprendizagem que ampliam as possibilidades das tecnologias mais clássicas como a lousa, o giz e o livro, disponíveis desde muito tempo nos espaços formais de ensino. O rápido desenvolvimento tecnológico das últimas décadas nos apresenta diversos recursos provenientes das novas tecnologias, como é o caso das tecnologias digitais, de modo que o desafio tem sido a implementação do ensino visando proporcionar condições mais favoráveis à aprendizagem dos estudantes.

164 DOI: Em andamento.

R. Bras. de Ensino de C\&T 
$\mathrm{O}$ aspecto interativo de muitas das novas tecnologias permite criar ambientes em que os alunos possam aprender fazendo, ao mesmo tempo em que recebem feedback e podem aprimorar continuamente seus conhecimentos construindo novos conhecimentos. Com essas tecnologias, conceitos difíceis de entender podem ser visualizados quando softwares de modelagem e simulação adequados são associados ao ensino. Estas tecnologias também permitem o acesso a uma infinidade de informações, como bancos de dados remotos, bibliotecas digitais, contato com profissionais especializados a qualquer distância, e facilitam o estabelecimento de vínculos entre a escola e a comunidade (BRANSFORD; BROWN; COCKING, 2000).

As tecnologias de informação e comunicação são importantes aliadas na promoção da educação que visa desenvolver nos estudantes habilidades para a construção do conhecimento, colaboração e pensamento crítico (HOWLAND, JONASSEN, MARRA, 2011). Contribuem, tanto para aumentar o acesso às informações, quanto como meio de promover a aprendizagem dos estudantes.

A tecnologia deve ser entendida como parceira intelectual, como colocam Howland, Jonassen e Marra (2011), e considerada como ferramenta de aprendizagem com a qual os alunos possam aprender como organizar e resolver problemas, compreender fenômenos novos, construir modelos desses fenômenos, e, dada uma situação nova, definir metas e regular sua própria aprendizagem. Esse também é um meio rico e flexível disponível para os alunos interagir e comunicar suas ideias trabalhando de modo colaborativo.

A interatividade é um dos aspectos mais relevantes que muitos dos recursos tecnológicos oferecem. A exemplo, a disponibilidade de um software de modelagem e simulação durante o estudo torna possível explorar um modelo de forma ágil, permitindo a manipulação de parâmetros ao mesmo tempo em que se visualiza a mudança gráfica e algébrica provocada, além de outras propriedades. A possibilidade de manipular modelos dinâmicos ao invés de estáticos favorece um melhor entendimento dos conceitos relacionados.

Dentre os recursos disponíveis que contemplam características já mencionadas, estão os programas que permitem a realização de videoanálise. Um exemplar de reconhecida qualidade e com a característica adicional de ser um software livre é o Tracker: video analysis and modeling tools (http://www.cabrillo.edu/ dbrown/tracker/), possibilita a videoanálise e construção de modelos de fenômenos físicos. Desenvolvido com tecnologia Java, tem a característica de ser multiplataforma. Após carregar um vídeo, que pode ser produzido de forma simples, com qualquer câmera digital, por exemplo, o programa oferece opções de selecionar um conjunto de quadros para ser analisado, bem como as variáveis de interesse para a obtenção do modelo e, a partir daí exibe um conjunto de dados numéricos. 
Alguns dos atributos da videoanálise com o Tracker são: possibilita múltiplas representações de um fenômeno em uma mesma tela - vídeo, tabela de dados, gráficos, equações -; permite a manipulação de referenciais, como os eixos coordenados; auxilia na compreensão da influência das escalas na interpretação de fenômenos físicos; analisa mais de um objeto no mesmo sistema, simultaneamente; e, viabiliza a realização de experimentos com baixo custo (HEIDEMANN; ARAUJO; VEIT, 2012).

Algumas precauções devem ser tomadas na produção ou escolha do vídeo para que haja fidelidade dos dados com o fenômeno tal como observado, sejam elas: definir os objetivos previamente, para que o filme expresse os aspectos relevantes; escolher ambiente com contrastes, sem excesso de iluminação, para que o ponto de interesse se destaque no cenário; estabelecer medida de referência no cenário, a partir da qual as escalas são definidas pelo Tracker; posicionar a câmera sem movimentá-la, com a perspectiva adequada para a análise; não usar zoom digital, que influencia na definição das escalas.

Informações sobre a aplicação do software e especificações de alguns de seus recursos são tratados na seção que descreve as atividades de modelagem, entre elas, voltamos a mencionar os cuidados com a adequação no planejamento do vídeo, que pode influenciar na veracidade do modelo. Isso ocorre, pois as imagens geradas na produção do vídeo correspondem a signos do fenômeno. Ao tratarmos de signos tomamos como referência os estudos realizados na semiótica peirceana.

\section{Semiótica: ciência dos signos}

A semiótica peirceana foi desenvolvida por Charles Sanders Peirce que considera o signo como algo, que para uma pessoa, toma lugar de outra coisa, não em todos os aspectos desta coisa, mas somente de acordo com certa forma ou capacidade. A 'coisa' a que o signo se reporta, na semiótica peirceana, é o objeto. Peirce (2005) denota o objeto como "uma coisa singular existente e conhecida ou que se acredita tenha anteriormente existido ou que se espera venha a existir" (p. 48). Nestes desdobramentos, Peirce (1972, p. 94) concebe signo (ou representámen) como

"algo que, sob certo aspecto ou algum modo, representa alguma coisa para alguém. Dirige-se a alguém, isto é, cria na mente dessa pessoa um signo equivalente ou talvez um signo melhor desenvolvido. Ao signo, assim criado, denomino interpretante do primeiro signo. $O$ signo representa alguma coisa, seu objeto. Coloca-se no lugar desse objeto, não sob todos os aspectos, mas com referência a um tipo de ideia que tenho, por vezes, denominado o fundamento do representámen". 
A abordagem peirceana com relação ao signo é ternária na qual identifica três elementos - representámen (signo), objeto e interpretante. Para Peirce, o signo está em movimento constante, pertencente a uma série de códigos que estão sempre em transformação. Peirce não estuda os signos, mas a semiose, ou seja, o efeito que o signo produz em uma mente interpretadora - a do intérprete.

Para Peirce (2005), o ser humano corresponde a uma mente interpretadora e somente reconhece o mundo pelo fato de representá-lo de alguma forma. O ser humano somente interpreta essa representação de mundo por meio de uma outra representação. A essa 'nova' representação, Peirce chama interpretante da primeira. $O$ interpretante é algo que se cria na mente do ser humano (intérprete). O interpretante, segundo Santaella (2005, p. 43), "não é qualquer signo, mas um signo que interpreta o fundamento". É por meio da interpretação evidenciada no interpretante que o fundamento do signo revela algo sobre o objeto existente. Neste sentido, Otte (2011, p. 315), chama a atenção para o fato de que as "pessoas são partes de um processo contínuo de interpretação e comunicação que se eleva acima do subjetivo".

$\mathrm{Na}$ tricotomia que articula signo, objeto e interpretante, a noção de objeto se biparte em imediato e dinâmico. Quando observamos na tela do computador o gráfico de uma parábola, estamos observando um signo, que representa algo em lugar de outra coisa. Em um contexto matemático, esse signo pode representar a função quadrática. Dessa forma, a função quadrática é o objeto dinâmico desse signo. Nesse caso, Santaella (2007, p. 15) afirma que "os signos só podem se reportar a algo, porque, de alguma maneira, esse algo que eles denotam está representado dentro do próprio signo". A maneira como o signo representado reporta-se àquilo a que ele se refere é o objeto imediato. "Ele se chama imediato porque só temos acesso ao objeto dinâmico através do objeto imediato" (SANTAELLA, 2007, p. 15). O objeto imediato do símbolo é o modo como o símbolo representa o objeto dinâmico, por meio de uma lei.

O estudo do interpretante nas tricotomias semióticas apresenta uma trifurcação: interpretante imediato, interpretante dinâmico e interpretante final. O interpretante imediato corresponde ao interpretante interno ao signo, refere-se ao potencial interpretativo do signo, da sua interpretabilidade ainda no nível abstrato. O interpretante dinâmico refere-se ao efeito singular que o signo produz em cada intérprete, envolvendo a dimensão psicológica do intérprete. $\mathrm{O}$ interpretante final refere-se ao resultado interpretativo. Nesse caso, chegamos ao limite pensável de um intérprete.

Para inferirmos sobre o limite pensável quando um intérprete se envolve com atividades de modelagem por meio da tecnologia é que foi proposto um minicurso com participantes de um evento regional de modelagem matemática e que apresentamos na próxima seção.

\section{Atividades de modelagem desenvolvidas}


As atividades de modelagem analisadas neste trabalho foram desenvolvidas durante 0 minicurso intitulado Atividades de Modelagem Matemática com o uso de Recursos Tecnológicos que ocorreu em 2012 durante um evento regional na área de Educação Matemática, ministrado por uma das autoras deste trabalho que doravante identificamos por Professora. Por se tratar de um curso de curta duração, no planejamento das atividades de modelagem levamos em conta que não conhecíamos de antemão o perfil dos participantes, por isso, o estudo contemplou conhecimentos matemáticos abordados desde o Ensino Fundamental, dado que o público do evento compreendia estudantes de graduação, professores da Educação Básica e professores de Graduação e Pós-Graduação.

Um levantamento inicial foi proposto aos vinte e três participantes inscritos no minicurso, de modo que permitisse uma visão geral do grupo, em relação à formação acadêmica, atuação profissional, conhecimento sobre modelagem matemática, uso de recursos tecnológicos no ensino, entre outros. Para esse fim, a professora lançou mão de um aplicativo on-line: o editor de formulários do Google Docs que permitiu a exibição em tempo real dos resultados do levantamento. A Figura 1 exibe o perfil dos participantes quanto à atuação profissional no âmbito do ensino.
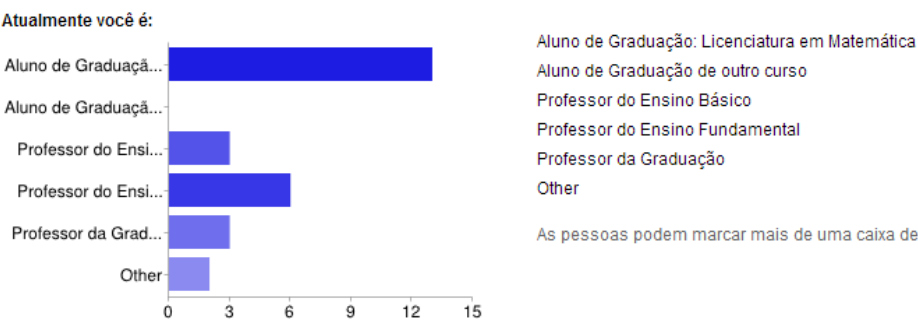

Figura 1 - Distribuição dos participantes quanto à atuação profissional.

(Fonte: Google Docs)

Uma consulta aos participantes mostrou que nenhum deles conhecia a videoanálise como um recurso didático, embora alguns tivessem conhecimento da aplicação dessa técnica em outras áreas, como no mercado financeiro ou na área esportiva.

A esse grupo foram propostas duas atividades de modelagem, ambas referentes ao movimento de corpos, com o propósito de problematizar e modelar as situações com o recurso da videoanálise. Inicialmente foi proposto o estudo do lançamento oblíquo de um corpo e ao final desse estudo realizado em conjunto, uma situação envolvendo o percurso de um carrinho de fricção foi sugerida. Essas atividades bem como o envolvimento dos participantes passam a ser descritas, conforme encaminhadas no minicurso.

Para nos referirmos aos participantes utilizamos a letra $\mathrm{P}$ acompanhada de um número, sendo que P1 corresponde ao participante 1, P2 ao participante 2 e, assim, sucessivamente. A professora que orientou o desenvolvimento da atividade é referenciada pela letra P. A coleta de 
dados para as análises que nos propusemos a realizar foi feita por meio de filmagem que nos possibilitou visualizar gestos e expressões dos participantes e da captura de imagens da tela do computador que consistem em signos que se remetem ao objeto.

\section{Atividade 1: Lançamento de um corpo}

A situação proposta na Atividade 1 consiste na ação de lançar uma bola para o alto e à frente. Inicialmente questionamos se essa situação poderia ser problematizada, então mencionamos outras ações que se remetem ao mesmo tipo de movimento, como o lançamento de uma bola à cesta no jogo de basquete ou o percurso de um projétil atirado por uma arma de fogo. Estas são situações que podem envolver uma problematização relevante, como o estudo de estratégias de jogo em um campeonato visando o bom desempenho de uma equipe perante outra, ou no trabalho da Polícia Científica. Assim, desenvolvemos uma atividade de modelagem estruturada de acordo com a sugestão de Almeida, Silva e Vertuan (2012).

Para o entendimento da situação, utilizamos um vídeo para que o movimento pudesse ser visto repetidas vezes, nas mesmas condições. Neste sentido, destacamos cada uma das fases na qual ocorreu e como ocorreu o desenvolvimento da atividade.

Situação inicial: Lançamento de uma bola para o alto e à frente em condições de tempo bom e sem ventos. O lançamento é feito de modo que se possa observar o trajeto da bola desde o início até que a mesma toque a calçada plana, paralela à parede vertical (Figura 2).

Fase de inteiração: Os dados obtidos com o Tracker são representados na Figura 2. Durante o percurso da bola no ar o programa permitiu registrar, em intervalos iguais de tempo, a posição da bola. Simultaneamente o Tracker ilustrou o gráfico, representando a variação da altura da bola em relação ao tempo e uma tabela com os valores de tempo, em segundos e altura, em centímetros. Para a obtenção dos dados foi necessário definir um sistema referencial. Para tanto, algumas considerações foram realizadas pela professora e pelos participantes do minicurso:

P: Como a calçada é meu plano aqui, eu não poderia colocar a bola exatamente no chão para fazer o lançamento... ela será lançada um pouco mais acima...

P5: Desculpa, mas quando tu... a bola já não foi lançada lá em cima? Eu já colocaria o eixo lá em cima...

P: Aqui? [levando o sistema de eixos para a posição inicial do percurso da bola, por meio do software]

P5: Não, mais pra baixo, de onde tu lançou a bola.

\section{$[\ldots]$}

R. B. E. C. T., vol 8, núm. 1, jan-abr.2015

DOI: Em andamento. 
P: P5, vou colocar o referencial aí [realizando o deslocamento do eixo] observe... o que que acontece?

P5: Tá, mas a altura da sua bola é lá de cima... ah, entendi.

P: Não, fala o que você percebeu aqui, o que acontece com o passar dos quadros? [indicando a origem do referencial] $O$ seu ponto zero é aqui né? Então a bola saiu daqui, ela subiu e...?

P5: ... ela desceu!

P: Ok, então vai ter um momento que você vai ter valores negativos para altura dessa bola, concorda?

P5: Aham.

P: Podemos trabalhar com esse referencial?

[Silêncio]

$P:$... nós podemos, desde que a gente saiba interpretar os resultados negativos que a gente vai ter para a altura dela...

[Participantes concordam]

Assim, foi considerado inicialmente o nível da calçada coincidindo com o eixo horizontal e o tempo zero como o primeiro quadro em que a bola não está na mão de quem a lançou. Além disso, foi necessário estabelecer uma medida conhecida no cenário para servir de parâmetro ao sistema, o bastão azul na Figura 2 indica a altura do desnível vertical na parede, com 60 centímetros.

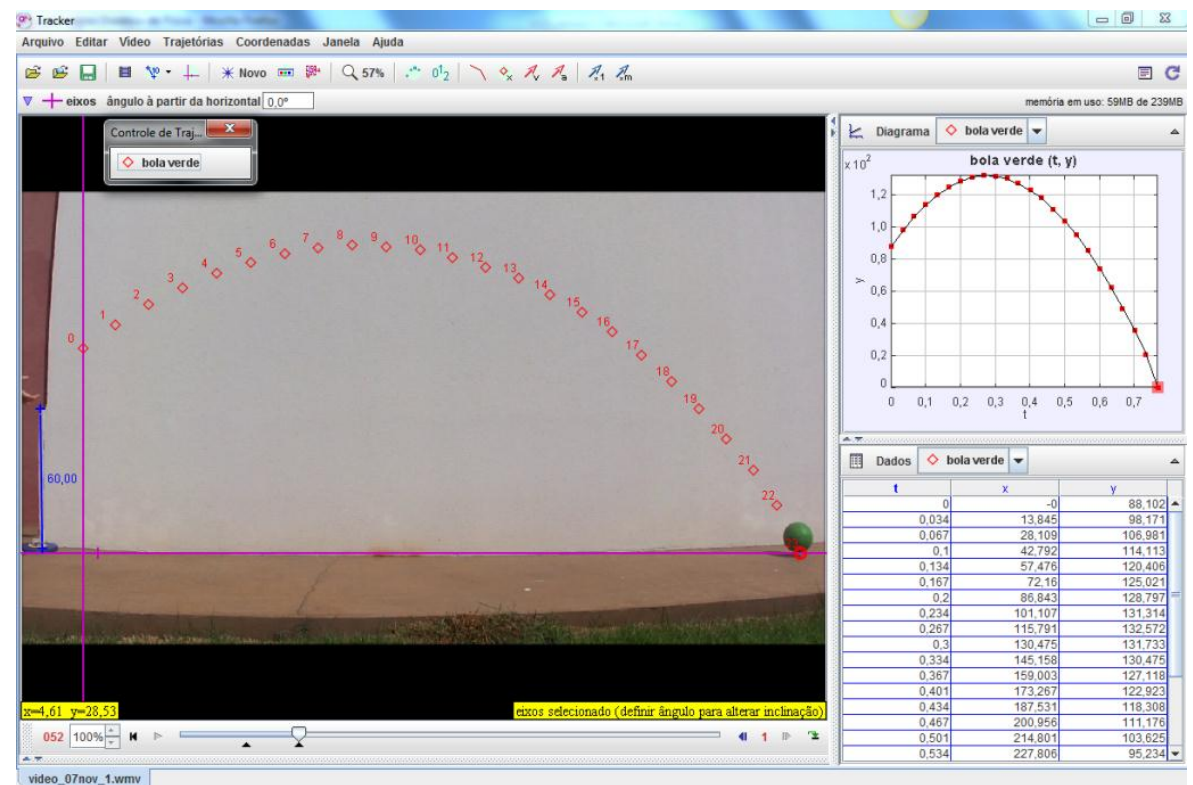

Figura 2 - Movimento da bola registrado pelo Tracker.

(Fonte: Imagem gerada por meio da captura de tela do Tracker) 
Em discussão com os participantes, ficou definido que uma problematização a ser estudada seria relacionada ao percurso da bola no ar, assim, deu-se prosseguimento na atividade.

Definição de um problema: determinar a relação entre altura atingida pela bola no decorrer do tempo, durante o período em que é lançada até atingir o chão.

\section{Matematização e resolução:}

a) Hipóteses: Pela observação do movimento da bola durante o tempo que permanece no ar podemos estabelecer algumas hipóteses iniciais:

$\mathrm{H}_{1}$ : não será considerada a resistência do ar;

$\mathrm{H}_{2}$ : a bola sobe até atingir uma altura máxima, a partir da qual começa a cair, de modo que a bola atinge alturas de mesmo valor, a partir daquela do lançamento, tanto na subida quanto na descida, em tempos equidistantes em relação àquele da altura máxima.

A curva de tendência indicada no gráfico nos leva a supor outra hipótese:

$\mathrm{H}_{3}$ : o modelo que descreve a variação da altura no decorrer do tempo é parabólico.

b) Variáveis: $t$ (tempo, em segundos); $y$ (altura atingida pela bola).

c) Modelo Matemático: Levando em consideração a hipótese de que o modelo é parabólico e as variáveis definidas, podemos escrever a expressão: $y=a t^{2}+b t+c$, em que $a, b$ e $c$ são parâmetros a definir a partir da situação estudada e do referencial adotado para a videoanálise.

Usando a ferramenta Data Tool temos algumas opções de ajuste de curvas. A Figura 3 mostra a opção pela parábola, que está representada pela linha contínua. Os parâmetros $a, b$ e são fornecidos pelo software, de modo que $y=-545,558 t^{2}+304,104 t+89,106$ é o modelo que atende as hipóteses e representa as alturas da bola em centímetros no decorrer do tempo, em segundos. 


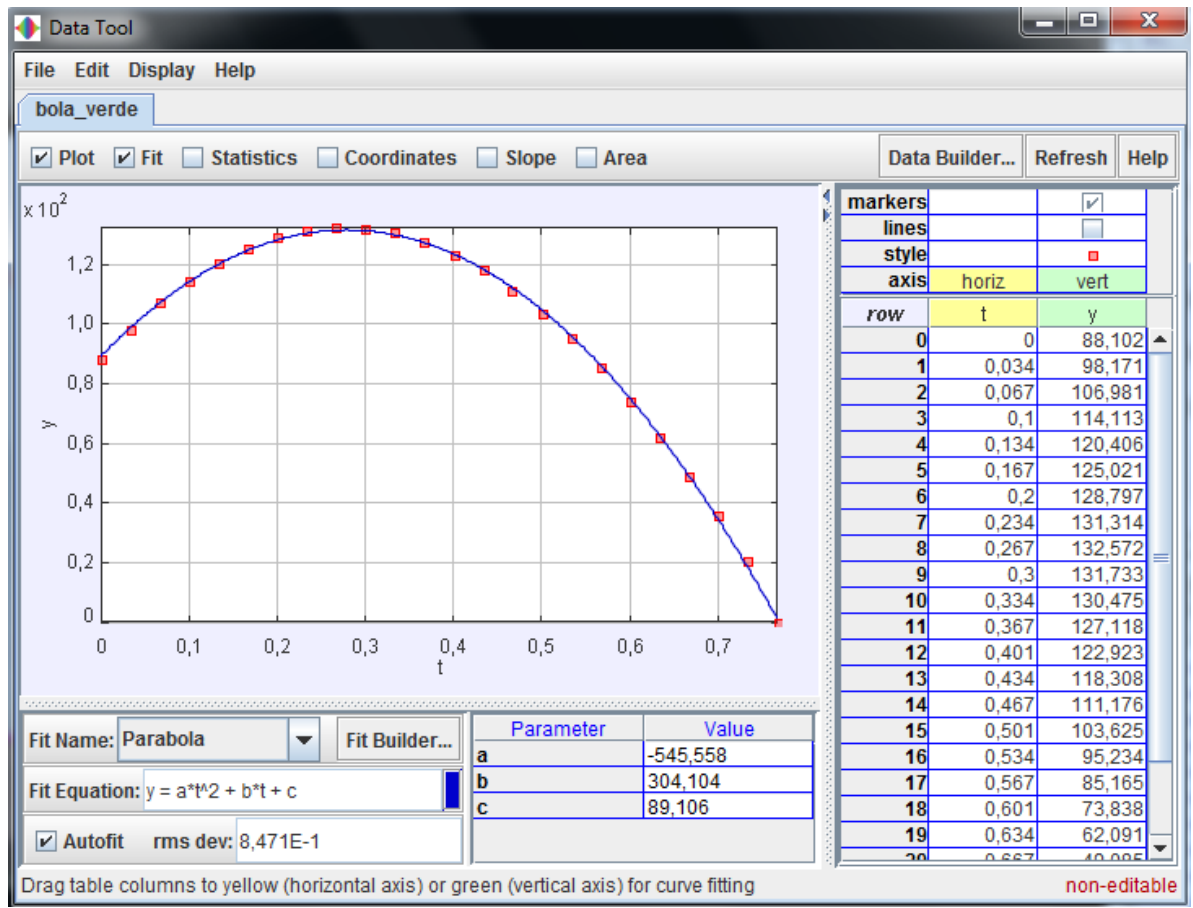

Figura 3 - Ferramenta de análise disponível no Tracker, para os dados coletados e representados a partir do vídeo.

(Fonte: Imagem gerada por meio da captura de tela do Tracker)

\section{Interpretação e validação}

A validação do modelo implica em comparar os resultados fornecidos pelo modelo com os reais. Se compararmos graficamente os pontos discretos com a curva contínua, podemos concluir que a hipótese de que o comportamento é descrito por uma parábola pode ser confirmada.

Para melhor visualizar a diferença dos resultados o cálculo do percentual de erro é exibido na Tabela 1, com os valores coletados na videoanálise e aqueles obtidos pelo modelo.

Observamos que, o erro percentual é bem pequeno, exceto nos três últimos valores da tabela. A diferença maior nesses pontos pode ter ocorrido devido à marcação manual do corpo de massa - denominado de bola verde - ou mesmo devido a uma deformação na imagem captada pela câmera. Porém, em termos de ajuste podemos afirmar que a parábola representa bem o fenômeno em estudo.

Para corroborar a hipótese da trajetória parabólica e o modelo obtido, podemos nos valer dos conceitos da Física, como o Princípio da Independência dos Movimentos, de Galileu. 
Tabela 1 - Comparativo dos dados obtidos pelo Tracker e os obtidos a partir do modelo matemático.

\begin{tabular}{|c|c|c|c|}
\hline$T$ & $y$ dados & $y$ modelo & Erro (\%) \\
\hline 0,000 & 88,102 & 89,106 & $-1,140$ \\
\hline 0,034 & 98,171 & 98,815 & $-0,656$ \\
\hline 0,067 & 106,981 & 107,032 & $-0,048$ \\
\hline 0,100 & 114,113 & 114,061 & 0,046 \\
\hline 0,134 & 120,406 & 120,060 & 0,287 \\
\hline 0,167 & 125,021 & 124,676 & 0,276 \\
\hline 0,200 & 128,797 & 128,104 & 0,538 \\
\hline 0,234 & 131,314 & 130,394 & 0,701 \\
\hline 0,267 & 132,572 & 131,409 & 0,877 \\
\hline 0,300 & 131,733 & 131,237 & 0,377 \\
\hline 0,334 & 130,475 & 129,816 & 0,505 \\
\hline 0,367 & 127,118 & 127,232 & $-0,090$ \\
\hline 0,401 & 122,923 & 123,325 & $-0,327$ \\
\hline 0,434 & 118,308 & 118,328 & $-0,017$ \\
\hline 0,467 & 111,176 & 112,142 & $-0,869$ \\
\hline 0,501 & 103,625 & 104,527 & $-0,870$ \\
\hline 0,534 & 95,234 & 95,928 & $-0,729$ \\
\hline 0,567 & 85,165 & 86,142 & $-1,147$ \\
\hline 0,601 & 73,838 & 74,816 & $-1,325$ \\
\hline 0,634 & 62,091 & 62,618 & $-0,849$ \\
\hline 0,667 & 49,085 & 49,231 & $-0,297$ \\
\hline 0,701 & 35,660 & 34,195 & 4,108 \\
\hline 0,734 & 20,557 & 18,396 & 10,512 \\
\hline 0,767 & 1,510 & 1,408 & 6,755 \\
\hline
\end{tabular}




\section{Situação Final:}

Podemos explorar o modelo para responder com mais precisão o comportamento da bola a qualquer tempo, assim como o tempo total de permanência da bola no ar.

Sabendo que quando a bola atinge o chão temos $y=0$, podemos calcular a que tempo isso ocorreu. Assim, de $-545,558 t^{2}+304,104 t+89,106=0$ vem $t_{1}=-0,212$ e $t_{2}=0,769$ segundos. Como a bola não foi lançada do chão, o valor de $t_{1}$ pode ser desconsiderado, pois inicialmente $t=0$ a bola estava a aproximadamente $y=89,106 \mathrm{~cm}$ do chão.

Observando a Tabela 1 podemos estimar a altura máxima atingida pela bola, embora não tenhamos certeza de qual é esse valor. Neste caso, o modelo auxilia na determinação precisa deste valor. Podemos usar $t_{1}=-0,212$ e $t_{2}=0,769$ para obter o tempo em que a bola atinge a altura máxima, que corresponde ao vértice da parábola: $t_{v}=0,278$ segundos, e a partir deste, obtemos $y_{v}=131,484 \mathrm{~cm}$.

Outro aspecto interessante que a videoanálise proporciona é a possibilidade de provocar alterações no referencial inicialmente adotado (posicionamento dos eixos coordenados) para discutir as alterações provocadas no modelo.

\section{Considerações sobre a atividade de modelagem}

A atividade como encaminhada acima poderia ser trabalhada com alunos do Ensino Médio, como um caso particular, ao estudar funções ou mesmo polinômios. Mas também poderia ser adaptada para outras situações do ensino, quando outros aspectos poderiam ser explorados: na graduação, além da obtenção desse modelo poderia ser explorado o conceito de derivada em um curso introdutório de Cálculo; ou, trabalhar com métodos de ajuste de curvas, como o dos mínimos quadrados ou interpolação polinomial, em uma disciplina de Cálculo Numérico.

Ressaltamos que nesta atividade o modelo foi obtido pelo software, mas que o professor poderia explorar a obtenção dos parâmetros $a, b$ e $c$ sem o auxílio do recurso computacional, para depois comparar com o obtido pelo software. Os encaminhamentos na atividade devem ser escolhidos de acordo com o objetivo do professor.

Nesta atividade, a hipótese de que a trajetória da bola é parabólica poderia vir da influência visual do movimento, dessa forma, propusemos outra situação para que esse aspecto pudesse ser observado e discutido.

\section{Atividade 2: Percurso de um carrinho de friç̧ão}

A Atividade 2 foi desenvolvida parcialmente com os participantes do minicurso, devido a restrição de tempo, as fases de resolução, interpretação e validação não foram contempladas. No entanto, os encaminhamentos referentes à fase de inteiração e de matematização possibilitaram- 
nos vislumbrar interpretações referentes ao fenômeno em estudo. Tal atividade consiste no estudo do percurso realizado por um carrinho de fricção de acordo com sua desaceleração. Para o entendimento da situação, levamos um carrinho de fricção para o minicurso e utilizamos um vídeo para que o movimento fosse visto repetidas vezes, nas mesmas condições. Destacamos cada uma das fases na qual ocorreu e como ocorreu o desenvolvimento da atividade.

Situação inicial: Percurso de um carrinho de fricção. Inicialmente, na sala de aula, o carrinho foi posto em funcionamento de modo que os participantes compreendessem a situação a ser problematizada e posteriormente um vídeo de curta duração ilustrando o mesmo movimento foi exibido de modo a se observar o percurso, desde o início até o repouso do mesmo (Figura 4).

Fase de inteiração: Pensar sobre o modelo que representaria a nova situação apenas, pela observação do movimento, desencadeou um diálogo entre os participantes e a professora e alguns argumentos surgiram:

P: Agora um outro experimento diferente, um carrinho de friç̧ão... fricciono $e$ solto ele. Como vai se comportar o carrinho no decorrer do tempo? Que modelo matemático poderia estar relacionado. Acho que vocês não vão enxergar, mas vou soltar ele aqui [colocou o carrinho em movimento] ele vai, vai embora, mas qual é o comportamento dele no decorrer do tempo?

P7: Ele vai parando.

P: Vai diminuindo a velocidade? Óbvio né, vai diminuindo a velocidade. Como que a velocidade vai diminuindo? Como é essa variação? Pensa matematicamente, dá pra você supor algum modelo?

P1: Uma reta.

$P: E ́$ linear?

P3: Pode ser que sim, pode ser que não.

P: O que significa ser linear? A cada instante de tempo a redução na velocidade é igual ao instante anterior.

P3: Se houver a aceleração, daí seria quadrática né.

P: Será que é quadrática?

P3: Se tivesse aceleração.

P: Vamos pensar assim, você tem um carro, ele está a uma determinada velocidade e a partir de um determinado ponto, na plaquinha do quilômetro cem da rodovia, não acelera mais, deixa ele ir por conta, ateeeeeé parar, 
imagina que seja um plano, bonitinho, pra ficar mais simples o modelo, né. Como vai ser o deslocamento em relação ao tempo desse móvel até ele parar.

P8: Linear.

P: Linear? Então, essa é uma hipótese... Nós temos aqui um videozinho, ilustrando isso pra gente, para que o software de videoanálise ajude vocês a verificar essa hipótese inicial de que é linear... que é uma reta que representa esse movimento.

$[\ldots]$

P3: A desaceleração é constante, mas a velocidade acho que...

P1: Sim, mas...

P: Ela também vai sofrer a força da gravidade... vai ser um movimento uniformemente variado..

P1: la ser linear se você não usasse atrito.

$[\ldots]$

P: Então, os dois modelos, o mesmo modelo matemático em duas situações diferentes, né, e o mesmo modelo descreve as duas situações. E é interessante que o aluno veja... porque senão ele pode ficar influenciado pelo movimento. $O$ movimento é parabólico, eu tô vendo isso... o carrinho anda em linha reta, então o modelo é linear? Quer dizer: não é uma coisa imediata.

P1: Ah não, mas é que eu pensei no atrito desprezado, ai seria linear.

P: Então, uma hipótese que você colocasse ia influenciar sim no modelo.

P1: É.

P: Tem várias coisas assim, a se pensar.

Foi proposto então que a obtenção dos dados fosse conduzida por meio do Tracker, no percurso do carrinho desde o início do movimento até o seu repouso. Os dados obtidos são representados na Figura 5. Durante o percurso do carrinho o programa permitiu registrar, em intervalos iguais de tempo sua posição. Simultaneamente o Tracker ilustrou o gráfico, representando a variação da distância do carrinho em relação ao tempo e uma tabela com os valores de tempo, em segundos e distância, em centímetros. 


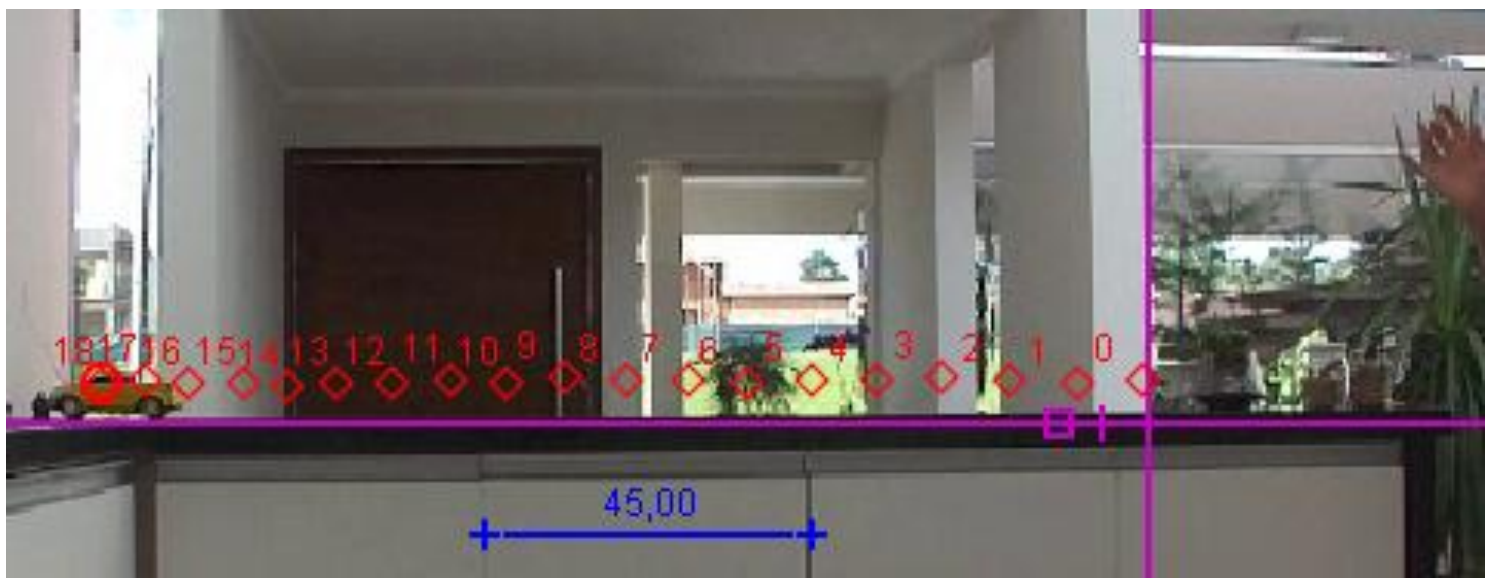

Figura 4 - Carrinho de friç̧ão em movimento.

(Fonte: Imagem produzida por meio da captura de tela do Tracker)

Definição de um problema: determinar a relação entre distância percorrida pelo carrinho no decorrer do tempo, durante o período em que inicia o movimento até obter novamente o repouso.

Matematização e resolução:

a) Hipóteses: Pela observação do movimento do carrinho durante o percurso e a análise do gráfico apresentado no Tracker (Figura 5) podemos estabelecer algumas hipóteses iniciais:

$\mathrm{H}_{1}$ : não será considerado o atrito com a superfície;

$\mathrm{H}_{2}$ : o modelo que descreve a variação da distância no decorrer do tempo é linear.

b) Variáveis: $t$ (tempo, em segundos); y (distância percorrida pelo carrinho, em centímetros).

Modelo Matemático: Não houve consenso, a princípio, sobre o modelo que poderia descrever o movimento, assim, a videoanálise passou a influenciar na definição pelo modelo. Durante o percurso do carrinho o programa permitiu registrar sua posição, em intervalos iguais de tempo (Figura 5). Simultaneamente o Tracker ilustrou o gráfico, representando a variação da distância do carrinho em relação ao tempo. A medida que os pontos eram marcados no gráfico a hipótese $\mathrm{H} 2$ foi sendo refutada e uma nova hipótese foi considerada - H3: o modelo que descreve a variação da distância no decorrer do tempo é quadrático. 


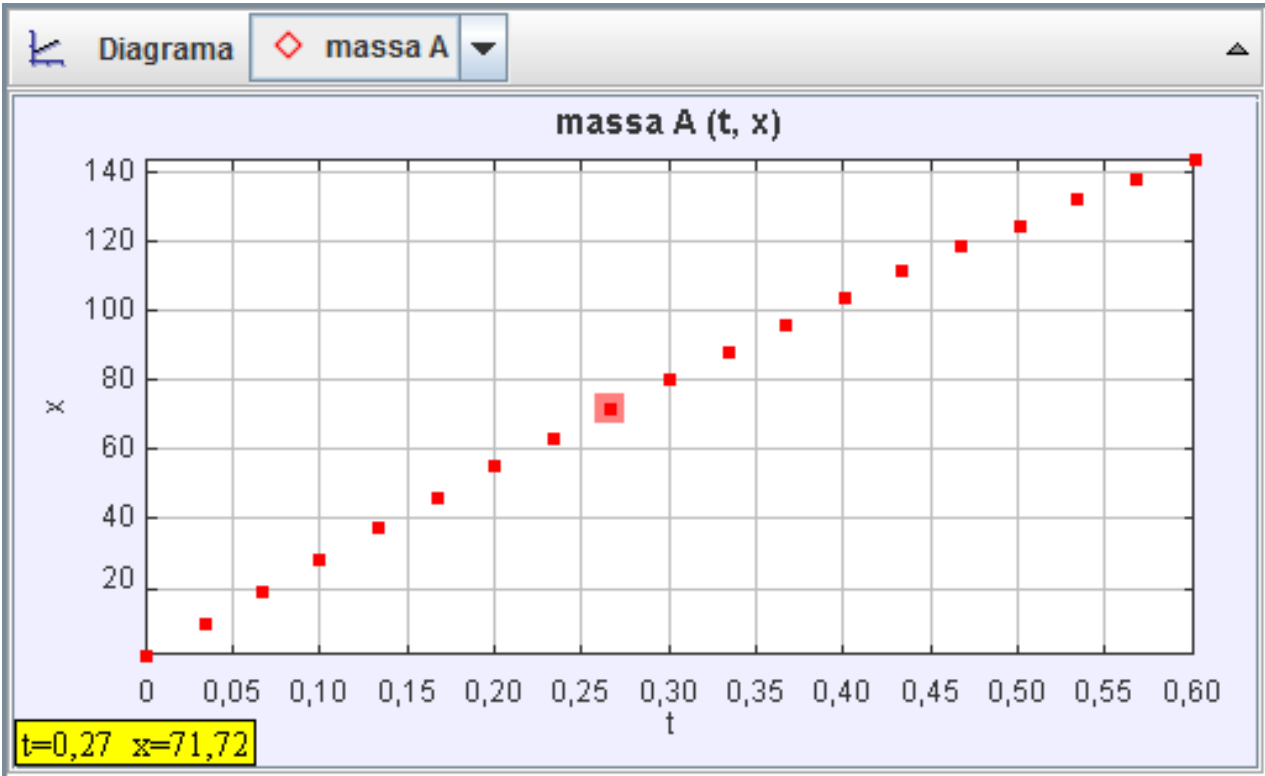

Figura 5 - Ferramenta de análise disponível no Tracker, para os dados

coletados e representados a partir do vídeo.

(Fonte: Imagem gerada por meio da captura de tela do Tracker)

A ferramenta de análise foi usada para testar as Hipótese $\mathrm{H}_{2}$ e $\mathrm{H}_{3}$ e a Figura 6 ilustra o comparativo dos ajustes linear (a) e quadrático (b).

(a)

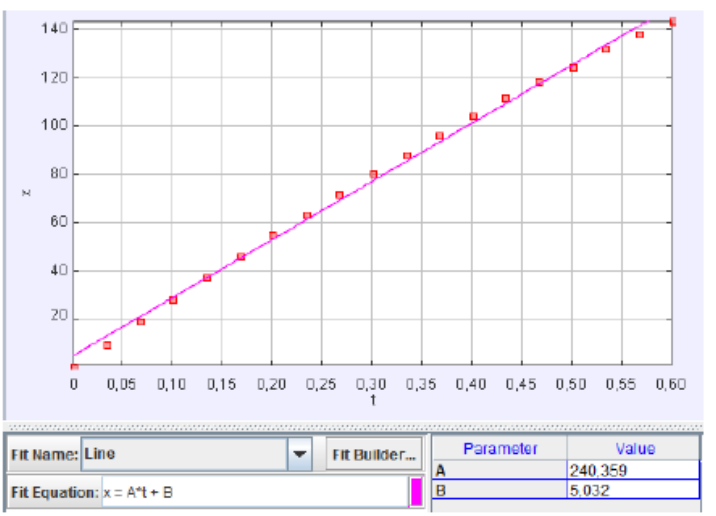

(b)

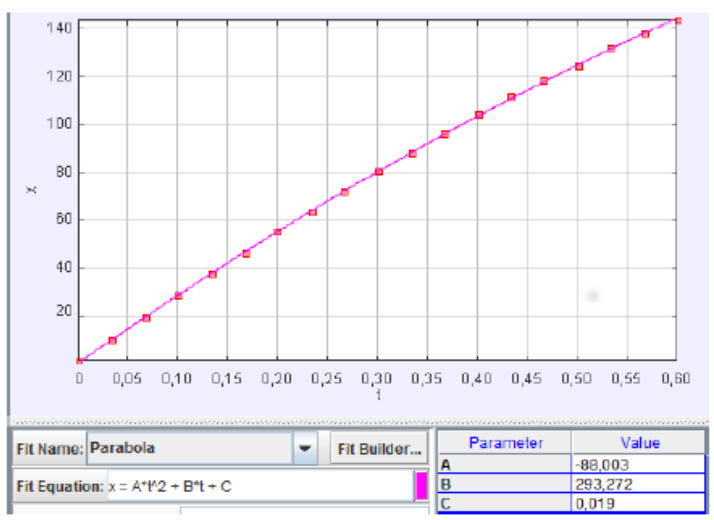

Figura 6 - Ferramenta de análise disponível no Tracker, para os dados coletados e representados a partir do vídeo.

(Fonte: Imagem gerada por meio da captura de tela do Tracker)

Desse modo, levando em consideração a hipótese de que o modelo é quadrático e as variáveis definidas, podemos escrever a expressão: $y=a t^{2}+b t+c$, em que $a, b$ e $c$ são parâmetros a definir a partir da situação estudada e do referencial adotado para a videoanálise. Esses parâmetros podem ser observados na Figura 6 (b) e levam ao modelo $y=-88,003 t^{2}+$ $293,272 t+0,019$. 


\section{Considerações sobre a atividade de modelagem}

Embora a atividade não tenha perpassado por todas as fases da modelagem como caracterizadas por Almeida, Silva e Vertuan (2012), seu encaminhamento permitiu vislumbrar um movimento que empiricamente sugere uma função linear, mas que com uma análise por meio do uso da tecnologia possibilita relacioná-lo a uma função quadrática. Tal atividade como inicialmente encaminhada poderia ser trabalhada com alunos do Ensino Médio.

Ressaltamos também que nesta atividade o modelo foi obtido pelo software, mas o professor poderia explorar a obtenção dos parâmetros $a, b$ e $c$ sem 0 auxílio do recurso computacional, para depois comparar com o obtido pelo software.

\section{Articulação entre tecnologia e semiótica nestas atividades de modelagem}

No estudo de um fenômeno, o ser humano (intérprete) ao fazer uma abordagem a priori do que o fenômeno representa, leva em consideração suas vivências, seu contato com situações passadas que interferem na produção de signos com relação ao que está sendo analisado. Com isso, a experiência do intérprete pode influenciar de maneira positiva ou negativa dependendo do fenômeno em estudo.

Investigar os signos interpretantes produzidos por esses intérpretes em atividades de modelagem matemática, ao fazer uso da tecnologia, nos revela a relevância desse recurso para a ressignificação de conceitos já construídos. Na atividade 1, a experiência dos participantes (intérpretes) com percursos de objetos lançados para o alto e à frente possibilitou a produção de signos interpretantes coerentes para a situação em estudo. O signo do trajeto realizado pelo objeto consiste em "algo que, sob certo aspecto ou algum modo, representa alguma coisa para alguém (PEIRCE, 1972, p. 94) - um signo matemático - para professores e/ou estudantes de matemática. Nesse âmbito, produziram signos interpretantes relacionados a uma parábola, uma função quadrática.

No estudo desse fenômeno, o uso da tecnologia possibilitou 'confirmar' a hipótese que tinham de antemão. $\mathrm{O}$ objeto imediato visualmente atrelado à situação está em consonância com o objeto dinâmico - função quadrática. O trajeto da bola representa o objeto matemático. Os signos interpretantes produzidos pelos participantes correspondem ao limite pensável e, desse modo, referem-se ao resultado interpretativo que os intérpretes estabeleceram com o objeto.

$\mathrm{Na}$ atividade 2, a experiência com relação ao espaço percorrido por um veículo de acordo com o tempo, levando em consideração uma aceleração nula interferiu na obtenção do modelo matemático da situação em estudo, ou seja, do modelo matemático para o percurso de um carrinho de friç̧ão.

R. B. E. C. T., vol 8, núm. 1, jan-abr.2015 ISSN - 1982-873X

DOI: Em andamento. 
Empiricamente, a observação do movimento realizado pelo carrinho parece levar os participantes a produzirem signos interpretantes imediatos que não condizem, matematicamente, ao fenômeno em estudo, uma vez que parece que os participantes não consideram o 'parar' como uma desaceleração. Isso fica evidente, principalmente, por não associarem a desaceleração como uma 'aceleração', conforme argumento apresentado por P3 "Se houver a aceleração, daí seria quadrática né". De certa forma, os signos interpretantes produzidos por P3 se remetem ao objeto matemático que representa a situação em estudo, no entanto, esse participante não está confiante no que declarou.

De forma geral, o que pudemos inferir foi que os participantes associaram a função linear ao trajeto de um carrinho de fricção e, neste caso, o objeto imediato correspondente ao percurso não representa o objeto dinâmico - função quadrática - que denota a situação. Para tanto, o uso da tecnologia permitiu aos participantes relacionar a situação estudada com o objeto matemático em que interagiram com signos. Esses 'novos' signos produziram efeitos interpretativos (semiose) na mente dos intérpretes, possibilitando a produção de signos interpretantes que correspondem ao objeto matemático função quadrática. Isso fica evidente quando, a medida em que os pontos eram marcados no gráfico a hipótese inicial $\left(\mathrm{H}_{2}-\right.$ o modelo que descreve a variação da distância no decorrer do tempo é linear) foi sendo refutada e a nova hipótese $\left(\mathrm{H}_{3}-\right.$ o modelo que descreve a variação da distância no decorrer do tempo é quadrático) foi considerada. A afirmação de P1 "Ah não, mas é que eu pensei no atrito desprezado, aí seria linear.", parece nos indicar que de certa forma houve uma ressignificação de conceitos já construídos a partir de experiências passadas sobre o fenômeno em estudo.

Embora a atividade 2 não foi finalizada durante o minicurso, a construção de uma hipótese nos permite inferir que, nesse caso, a tecnologia agiu como parceira intelectual, conforme proposto por Howland, Jonassen e Marra (2011), pois possibilitou a regulação dos encaminhamentos para a compreensão do fenômeno via matemática.

Em suma, ao fazermos uma análise semiótica das atividades de modelagem mediadas pelo uso da tecnologia, mais precisamente do uso da videoanálise, pudemos inferir que os signos que o computador possibilita produzir auxiliam na produção de signos interpretantes pelos intérpretes que condizem com o objeto dinâmico da situação.

\section{Considerações finais}

O debate em torno das contribuições da Modelagem Matemática para os ambientes educacionais já é conclusivo no sentido de sua eficácia, quando as atividades são encaminhadas segundo diversas perspectivas que tem sido objeto de investigação da comunidade científica. Assim, reconhecemos que o momento é propício para aprofundarmos o debate em torno da 
teorização dos processos envolvidos no fazer modelagem. Nesse sentido, olhar para a prática de modelagem à luz de outras teorias educacionais abre novas perspectivas às pesquisas.

Com este trabalho, nosso intuito foi de nos valer de conceitos da Semiótica Peirceana para inferir como os signos interpretantes são produzidos quando atividades de modelagem ocorrem em um ambiente mediado por certos recursos tecnológicos. Uma análise pontual permitiu-nos inferir que os participantes (intérpretes) produziram de imediato, signos distintos ao refletirem sobre o movimento de corpos em duas situações diferentes, porém que estão relacionados ao mesmo objeto matemático. Os signos adequados foram produzidos pelos intérpretes após o uso da videoanálise que possibilitou a observação dos fenômenos sob a perspectiva dos dados coletados e suas diferentes representações (valores numéricos tabelados, e simultânea visualização gráfica), que fizeram emergir o objeto matemático representado em cada movimento: a função quadrática, que é o objeto dinâmico desse signo.

O propósito de investir esforços em estudos que avaliem como a tecnologia, entendida como parceira intelectual, interfere na produção de signos interpretantes pelos alunos em atividades de modelagem ao problematizarem, experimentarem, planejarem, construírem modelos, visualizarem resultados, interagirem com os outros é promissor para os propósitos da Educação Matemática.

É de se considerar o limite da pesquisa com relação à produção de signos interpretantes para o objeto matemático função quadrática quando levamos em consideração o fenômeno trajeto percorrido, pois nosso foco foi destacar o uso da tecnologia enquanto parceira intelectual nestas situações. Uma análise dessas mesmas situações articulando tecnologia e dedução do modelo matemático pode ser realizada em pesquisa posterior.

\section{Referências}

ALMEIDA, L. W. de; SILVA, K. P. da; VERTUAN, R. E. Modelagem Matemática na Educação Básica. São Paulo: Contexto, 2012.

ALMEIDA, L. M. W.; SILVA, K. A. P. O significado em atividades de modelagem matemática: um olhar sobre pesquisas brasileiras. Revemat. Florianópolis, v. 9, ed. temática, p. 124-145, jun. 2014. BERGER, M. A semiotic view of mathematical activity with a Computer Algebra System. RELIME Revista Latinoamericana de Investigacion en Matematica Educativa. Comitê Latinoamericano de Matemática Educativa, Distrito Federal, México, v. 13, n. 2, p. 159-186, 2010.

BRANSFORD, J. D.; BROWN, A. L.; COCKING, R. R. (Ed.). How People Learn: Brain, Mind, Experience, and School: Expanded Edition. Washington: National Academy Press, 2000. 385 p. CUNNINGHAM, D. J.; KEHLE, P. E. Cognitive Semiotics in Education. Recherches en communication. n. 19, 2003. 
GALBRAITH, P. Models of Modelling: Genres, Purposes or Perspectives. Journal of Mathematical Modelling and Application, 5(1), 2012, 3-16.

HEIDEMANN, L. A.; ARAUJO, I. S.; VEIT, E. A.. Ciclos de Modelagem: uma alternativa para integrar atividades baseadas em simulações computacionais e atividades experimentais no ensino de Física. Caderno Brasileiro de Ensino de Física, v. 29, p. 965-1007, 2012.

HOWLAND, J. L.; JONASSEN, D.; MARRA, R. M.. Meaningful Learning with Technology. 4. ed. Boston: Pearson, 2011. 292 p.

LESH, R.. Tools, Researchable Issues \& Conjectures for investigating what it means to Understand Statistics (or Other Topics) Meaningfully. Journal of Mathematical Modelling and Application, 2(1), 2010, 16-48.

MANECHINE, S. R. S.; CALDEIRA, A. M. A. Construção de conceitos matemáticos na Educação Básica numa abordagem Peirceana. Bolema. Rio Claro, v. 23, n. 37, p. 887-904, dez. 2010.

OTTE, M. F. Evolution, learning, and semiotics from a Peircean pont of view. Educational Studies in Mathematics. Springer, v. 77, n. 2-3, p. 313-329, 2011.

PEIRCE, C. S. Semiótica. Tradução de José Teixeira Coelho Neto. 2. reimpr. da 3. ed. de 2000. v. 46. São Paulo: Perspectiva, 2005. (Estudos).

PEIRCE, C. S. Semiótica e Filosofia: textos escolhidos. Tradução de Octanny Silveira da Mota e Leonidas Hegenberg. São Paulo: Cultrix, 1972.

SANTAELLA, L. Matrizes da linguagem e pensamento: sonora visual verbal: aplicações na hipermídia. 3. ed. São Paulo: Iluminuras: FAPESP, 2005.

SANTAELLA, L. Semiótica aplicada. São Paulo: Thomson Learning, 2007.

STEINBRING, H. What makes a sign a Mathematical Sign?: an epistemological perspective on mathematical interaction. Educational Studies in Mathematics. Springer, v. 61, p. 133-162, 2006.

\footnotetext{
Karina Alessandra Pessoa da Silva. Licenciada em Matemática pela Universidade Estadual de Londrina, Mestre e Doutora em Ensino de Ciências e Educação Matemática pela Universidade Estadual de Londrina. Docente da Universidade Tecnológica Federal do Paraná, câmpus Londrina e do Programa de Pós-Graduação Mestrado Profissional em Ensino de Matemática. Membro da Diretoria Regional do Paraná, Sociedade Brasileira de Educação Matemática (SBEM-PR). E-mail: karinasilva@utfpr.edu.br
}

Adriana Helena Borssoi. Licenciada em Matemática pela Universidade Estadual do Oeste do Paraná, Mestre e Doutora em Ensino de Ciências e Educação Matemática pela Universidade 
Estadual de Londrina. Docente da Universidade Tecnológica Federal do Paraná, câmpus Londrina e do Programa de Pós-Graduação Mestrado Profissional em Ensino de Matemática. E-mail: adrianaborssoi@utfpr.edu.br

Lourdes Maria Werle de Almeida. Licenciada em Matemática pela Universidade Estadual do Oeste do Paraná, Mestre em Matemática pela Universidade Estadual de Londrina e Doutora em Engenharia de Produção pela Universidade Federal de Santa Catarina. Docente da Universidade Estadual de Londrina, atuando no curso de graduação em Matemática e no Programa de PósGraduação em Ensino de Ciências e Educação Matemática. Coordenadora do Grupo de Pesquisa sobre Modelagem Matemática e Educação Matemática (GRUPEMMAT). E-mail: lourdes@uel.br 